\title{
PELATIHAN PENGOLAHAN JAMUR TIRAM MENJADI PRODUK (ABON DAN KERIPIK) YANG BERGIZI DAN BERNILAI EKONOMI TINGGI SEBAGAI UPAYA PENINGKATAN PENDAPATAN MASYARAKAT DI DESA TANJUNG GUNUNG KELURAHAN GERUNG SELATAN
}

\author{
Sri Puji Astuti, ${ }^{1)}$ Ayuni Sukarman ${ }^{2)}$, Cinthya Meita Putri ${ }^{3)}$, M. Rizki Juardi ${ }^{1)}$, dan M. Suhayat \\ Nail Hamdi3) \\ ${ }^{1)}$ Fakultas MIPA, ${ }^{2)}$ Fakultas Pertanian, ${ }^{3)}$ Fakultas Hukum Universitas Mataram \\ Jl. Majapahit No. 62 mataram \\ *) Korespondensi: spastuti@unram.ac.id
}

Diterima 2 April 2019 / Disetujui 19 Juni 2019

\begin{abstract}
ABSTRAK
Kegiatan pengabdian pada masyarakat dengan khalayak masyarakat di Desa Tanjung Gunung Kelurahan Gerung Selatan, Kecamatan Gerung Kabupaten Lombok Barat, telah selesai dilaksanakan. Tujuan dari kegiatan ini adalah memberikan pengetahuan dan keterampilan kepada warga masyarakat dalam mengolah jamur tiram menjadi produk (keripik dan abon) yang bergizi dan bernilai ekonomi tinggi, memotivasi warga menjadi enterpreneur dengan mengembangkan kreatifitas berbahan dasar jamur tiram. Metode pendekatan Focus Group Discussion digunakan dalam kegiatan ini yang mencakup sosialisasi, demontrasi, pelatihan, pembinaan dan evaluasi. Materi yang disampaikan meliputi hasil panen budidaya jamur tiram yang melimpah dan butuh penanganan, aneka olahan jamur tiram yang memiliki daya simpan lama, demonstrasi peralatan dan bahan yang dibutuhkan dalam pembuatan abon dan keripik jamur tiram, pelatihan pembuatan abon dan keripik jamur tiram. Sebanyak $95 \%$ peserta memahami materi-materi yang disampaikan, $90 \%$ peserta memahami cara pembuatan abon dan keripik jamur tiram, sebanyak $98 \%$ peserta termotivasi untuk mempraktikkan dan membuat kembali di rumah masing-masing, sebanyak $60 \%$ peserta termotivasi untuk mengembangkan kreativitas membuat produk lainnya dari bahan jamur tiram, dan sebanyak $80 \%$ peserta termotivasi untuk memasarkan produk abon dan keripik jamur tiram.
\end{abstract}

Kata Kunci : pengolahan jamur tiram, abon, keripik, Desa Tanjung Gunung

\section{PENDAHULUAN}

Tanjung Gunung merupakan salah satu Desa di kelurahan Gerung Selatan, Kecamatan Gerung, Kabupaten Lombok Barat, sebagian besar masyarakatnya bermata pencarian sebagai petani, peternak, dan pembudidaya jamur tiram. Budidaya jamur tiram belum lama ini digeluti oleh masyarakat Tanjung Gunung, produksi jamur tiram terus meningkat setiap pekannya, sekitar 20-30\% hasil panen dikonsumsi sendiri dan sisanya dijual ke pasar tradisional. Daya simpan jamur tiram segar sangat singkat, tidak berimbang antara waktu panen dengan jumlah hasil panen, sehingga jamur tiram yang dipanen harus segera dijual kepasaran agar tidak rusak dan membusuk. Sisa hasil panen yang tidak lulus sortis untuk di pasarkan akan dikonsumsi sendiri oleh petani. 
Secara umum petani biasanya memanfaatkan jamur tiram sebagai bahan masakan untuk lauk dengan cara di goreng atau di pepes, makanan ini pun memiliki daya simpan yang singkat, keterbatasan pengetahuan masyarakat mengenai aneka olahan jamur tiram mendorong tim pengabdian Universitas Mataram untuk mengadakan pelatihan mengenai pengolahan jamur tiram menjadi produk abon dan keripik yang bergizi dan bernilai ekonomi tinggi, sehingga masyarakat memiliki gambaran dan pengalaman dalam membuat olahan berbahan jamur tiram yang memiliki daya simpan lebih lama hingga berbulan-bulan lamanya, selain itu dapat meningkatkan nilai jual jamur tiram dan meningkatkan kesejahteraan masyarakat Tanjung Gunung.

Berdasarkan uraian analisis kondisi masyarakat tersebut, dapat diketahui beberapa permasalahan yang dihadapi oleh mitra dalam memanfaatkan hasil panen jamur tiram, diantaranya:

1. Hasil panen jamur tiram di jual langsung ke pasar tanpa melalui proses pengolahan produksi.

2. Jamur tiram yang tidak lulus sortir akan dikonsumsi pribadi oleh petani.

3. Jarak panen yang cepat dengan hasil yang melimpah tidak sejalan dengan waktu pemasaran.

4. Daya simpan, yang cukup singkat

5. Beberapa masyarakat tidak dapat mengkonsumsi jamur tiram secara langsung karena terkendala aroma.

6. Belum adanya program pemerintah yang menjangkau desa-desa dalam meningkatkan kualitas sumber daya para petani budidaya jamur tiram.

7. Bayak warga masyarakat yang belum memiliki pekerjaan tetap pada jenjang usia produktif dan non produktif.

$$
\text { Sehingga melalui kegiatan }
$$

pengabdian kepada masyarakat (PKM), dapat tercapainya target yang diharapakan meliputi:
1. Terciptanya pengembangan hasil panen jamur tiram oleh petani di Desa Tanjung Gunung

2. Jamur tiram dapat digunakan sebagai bahan untuk membuat abon dan keripik jamur.

3. Waktu pemasaran produk abon dan kripik jamur tiram lebih panjang dan dapat di stok.

4. Jamur tiram hadir dalam bentuk inovasi yang berbeda, berupa abon dan keripik yang bergizi dan rasa yang lebih enak.

5. Adanya program yang langsung menjangkau petani hulu sehingga dapat menambah dan meningkatkan perekonomian desa.

\section{METODE PELAKSANAAN}

Pelatihan pengolahan jamur tiram menjadi produk abon dan keripik yang bergizi dan bernilai ekonomi tinggi dengan sasaran ibu dan bapak petani jamur tiram, remaja Desa Tanjung Gunung, mitra Jamur Lombok yang membantu dalam distribusi serta mitra mahasiswa KKN tematik yang memfasilitasi tempat pelaksanaan kegiatan. Metode yang digunakan dalam kegiatan ini, adalah:

1. Sosialisasi, bertujuan untuk memberikan gambaran singkat, informasi, dan arahan kepada peserta kegiatan sebagai bentuk penguatan dalam mensukseskan kegiatan PKM.

2. Persiapan dilakukan oleh Mahasiswa KKN tematik Universitas Mataram, yang bertujuan untuk mengidentifikasi dan menyiapkan kebutuhan yang diperlukan selama kegiatan PKM.

3. Penyuluhan yang bertujuan untuk memberikan informasi kepada para peserta terkait dengan aneka makanan yang dapat dibuat dari bahan dasar jamur tiram yang disampaikan oleh ibu Sri Puji Astuti, S.Si,.M.Si selaku narasumber dari Universitas Mataram dan upaya distribusi dan olahan yang disampaikan oleh pengusaha sekaligus 
owner Jamur Lombok oleh bapak Agus Sutrisno, S.Kom.

4. Demonstrasi dan pelatihan pembuatan abon dan keripik berbahan dasar jamur tiram, peserta diberi contoh dan belajar melakukan sendiri teknik pengolahan jamur tiram menjadi abon dan keripik, yang dimulai dari tahap awal sampai tahap akhir yang meliputi proses pembersihan jamur, penyuiran, persiapan bumbu-bumbu, pencampuran dengan tepung dan bumbu, penggorengan, spinner, pendinginan dan pengemasan.

5. Monitoring dan evalusi pada sekaligus dilakukan terhadap ketercapaian tujuan dan sasaran kegiatan, melalui wawancara dan observasi langsung saat kegiatan berlangsung.

6. Pendampingan dilakukan secara terstruktur oleh mitra guna menjaga keberlanjutan kegiatan dan manajemen distribusi

\section{HASIL DAN PEMBAHASAN}

Kegiatan pelatihan pengolahan jamur tiram menjadi abon dan keripik yang bergizi dan bernilai ekonomi tinggi di Desa tanjung Gunung dimulai sejak bulan Februari 2019. Kegiatan ini diawali dengan tahap sosialisasi ke masyarakat desa mengenai aneka olahan makanan berbahan dasar jamur tiram, kemudian dilanjutkan dengan tahap persiapan waktu dan tempat, serta peralatan dan bahan yang diperlukan selama kegiatan. Tahap ketiga, dilakukan penyuluhan oleh para nasasumber terkait aneka olahan dan manajemen distribusi, selain itu para narasumber juga memberikan penguatan-penguatan mental dan jiwa yang harus dimiliki oleh seorang entrepreneur muda. Tahap keempat, dilanjutkan dengan kegiatan demonstrasi dan pelatihan dalam membuat abon dan keripik jamur tiram, dilakukan pendampingan secara langsung ke masyarakat sehingga dapat menjawab secara langsung pertanyaan-pertanyaan yang diajukan oelh para peserta. Monitoring dilakukan dengan membandingkan ketercapaian kegiatan dengan indikator yang telah ditentukan terlebih dahulu, adapun indikator yang diperoleh meliputi:

a. Sebanyak $95 \%$ peserta memahami materi-materi yang disampaikan,

b. $90 \%$ peserta memahami cara pembuatan abon dan keripik jamur tiram,

c. sebanyak $98 \%$ peserta termotivasi untuk mempraktikkan dan membuat abon dan keripik di rumah masing-masing,

d. sebanyak $60 \%$ peserta termotivasi untuk mengembangkan kreativitas membuat produk lainnya dari bahan jamur tiram, dan,

e. sebanyak $80 \%$ peserta termotivasi untuk memasarkan produk abon dan keripik jamur tiram.

f. Pendampingan dalam pemasaran dan distribusi terus dilakukan oleh mitra dari Jamur Lombok guna menjaga keberlanjutan produksi dan usaha.

Proses pembuatan abon jamur tiram secara berurutan ditampilkan pada Gambar 1, Gambar 2, Gambar 3, Gambar 4, Gambar 5 , sedangkan proses pembuatan keripik jamur tiram secara berurutan ditampilkan pada Gambar 6, Gambar 7, Gambar 8, Gambar 9, dan Gambar 10.

Proses Pembuatan abon jamur tiram.

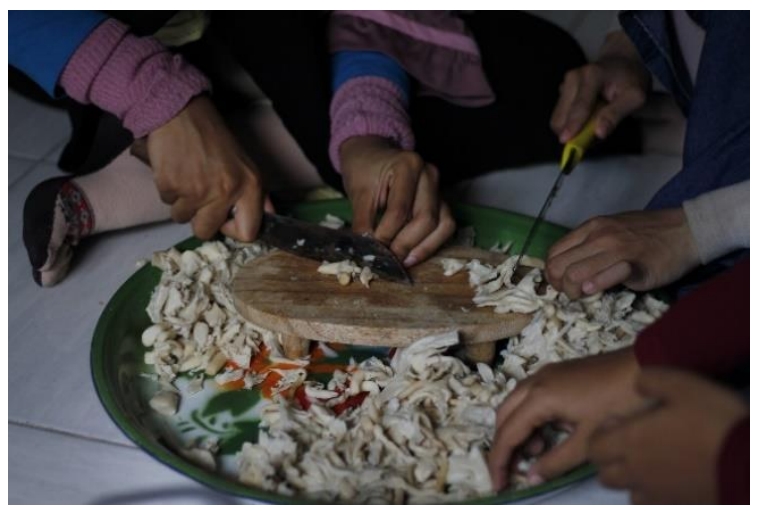

Gambar 1. Proses pengirisan jamur tiram 


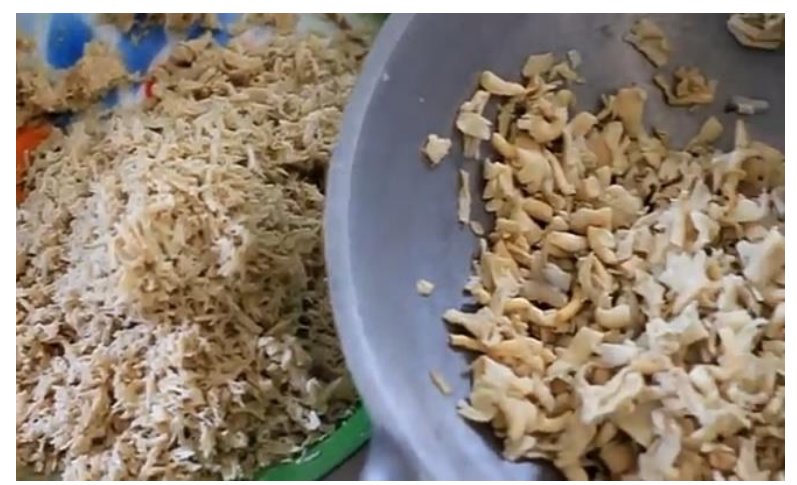

Gambar 2. Jamur tiram yang telah diberi bumbu dan siap digoreng

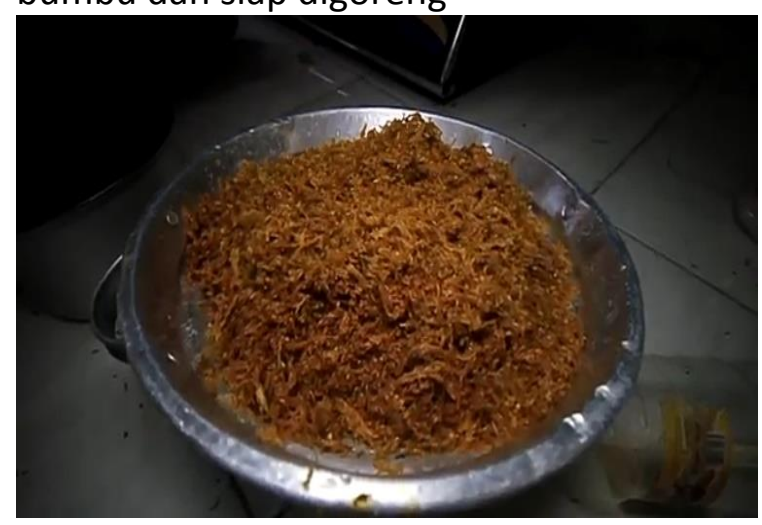

Gambar 3. Abon yang telah matang

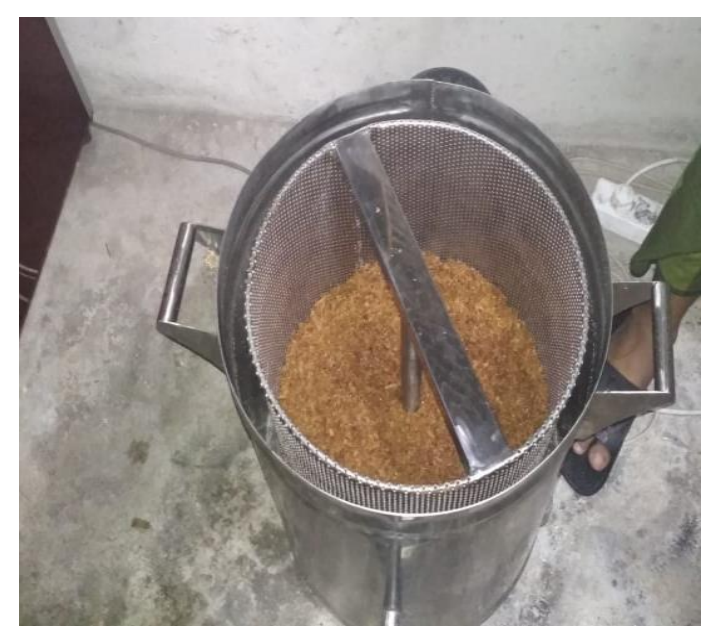

Gambar 4. Proses spiner

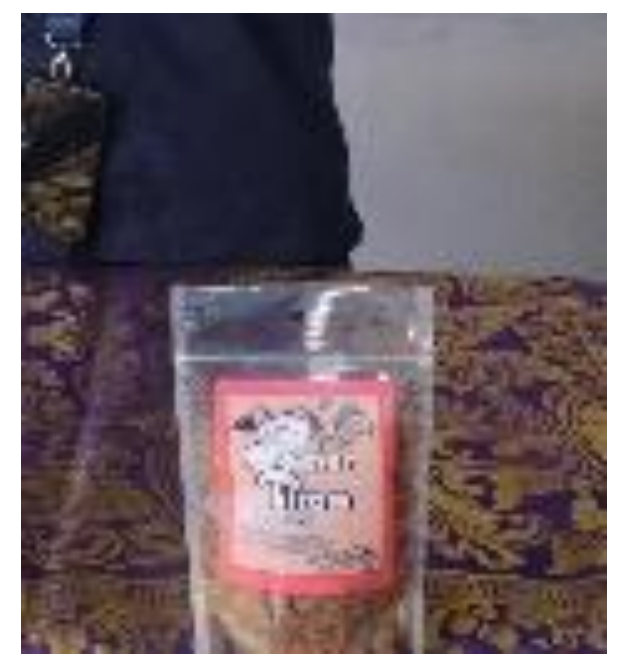

Gambar 5. Abon yang telah dikemas

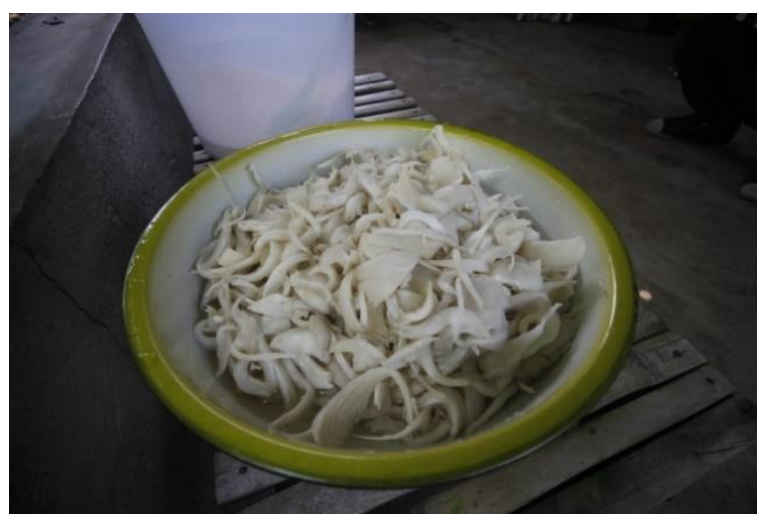

Gambar 6. Jamur tiram yg sudah dibersihkan dan disuir-suir terlebih dahulu.

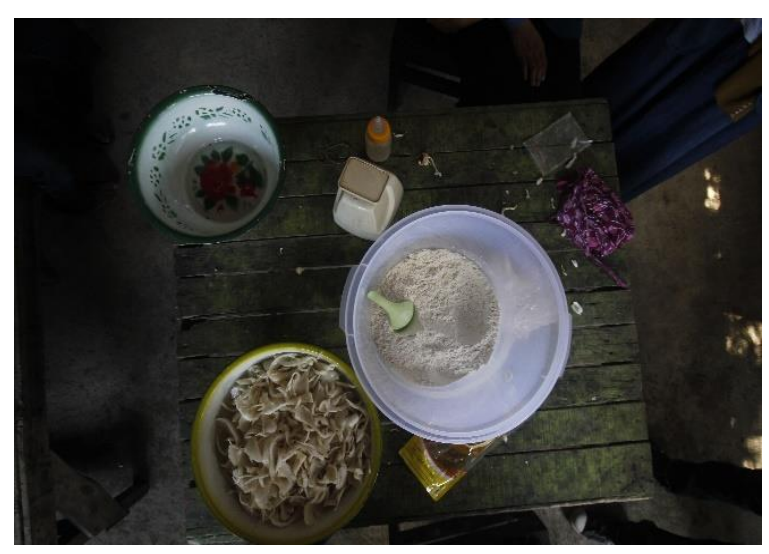

Gambar 7. Proses pencampuran tepung dan rempah-rempah. 


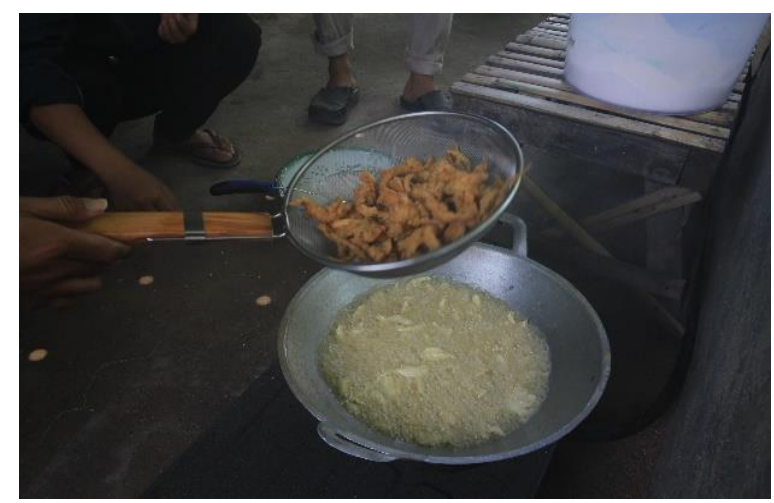

Gambar 8. Proses penggorengan keripik

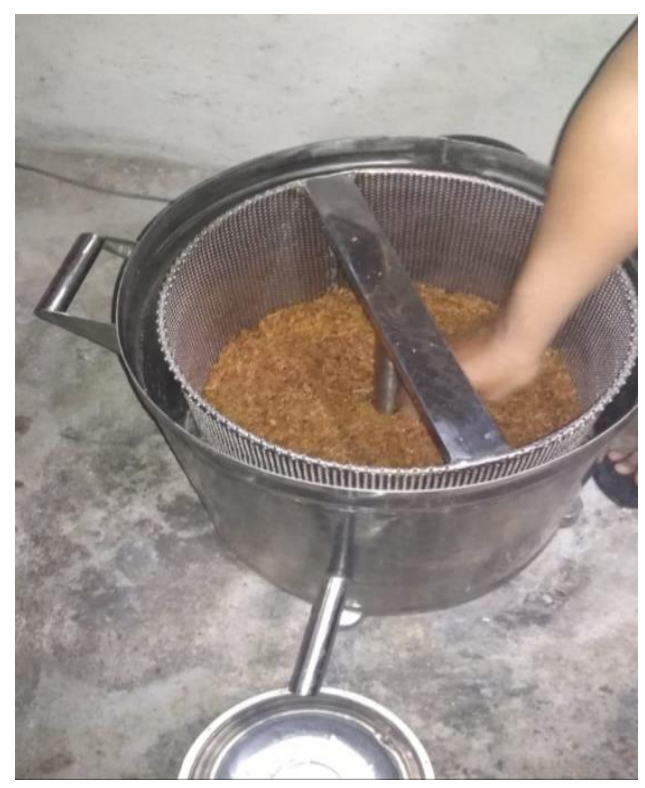

Gambar 9. Proses spinner



Gambar 10. Kripik yang siap dikemas

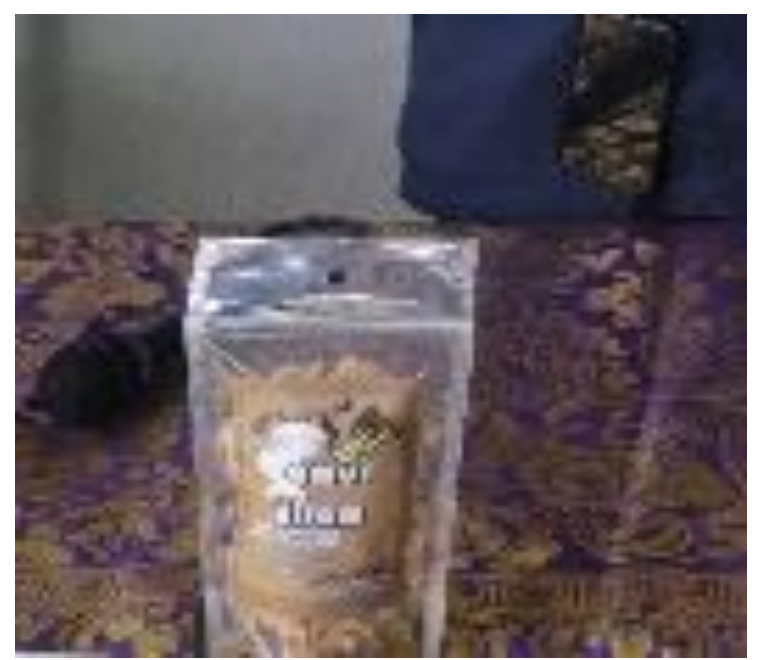

Gambar 11. Kripik yang telah dikemas

Melalui pelatihan pengolahan jamur tiram menjadi produk keripik dan abon yang bergizi dan bernilai ekonomi tinggi, diharapkan masyarakat dapat termotivasi untuk memanfaatkan peluang berbisnis jamur tiram, baik yang sudah di olah maupun yang belum.

Pengolahan jamur tiram menjadi keripik dan abon membutuhkan waktu yang relatif lama sekitar 5 sampai 6 jam, tergantung volume pembuatan, tenaga yang digunakan serta kelengkapan alat dan bahan yang tersedia. Selama proses pengolahan dijumpai beberapa kendala diantaranya keripik dan abon mudah gosong jika perhatian tidak terfokus pada saat penggorengan, durasi waktu penggorengan dan besar kecilnya api kompor yang digunakan, takaran tepung yang kurang atau terlalu banyak dapat menyebabkan keripik mudah melempem.

Perlu juga diperhatikan selama proses spiner agar tidak terlalu kering, sehingga cita-rasa keripik tetap terjaga. Berbeda dengan produk abon yang harus benar-benar kering agar tetap gurih. Oleh karena itu, perlu dilakukan pembinaan dan pendampingan secara berkala agar masyarakat dapat mengembangkan keterampilan dalam pengolahan jamur tiram 
untuk dapat menghasilkan produk yang berkualitas dan tahan lama.

Hasil kegiatan PKM secara garis besar sudah mencakup beberapa komponen yang diharapkan, diantaranya: 1). Ketercapaian jumlah peserta dalam mengikuti kegiatan, 2). Ketercapaian tujuan pelatihan, 3). Ketercapaian materi yang disampaiakan, 4). Ketercapaian kemampuan peserta dalam memahami dan mempraktikkan materimateri yang telah disampaiakan.

\section{KESIMPULAN}

Kegiatan pelatihan pengolahan jamur tiram menjadi produk abon dan yang bergizi dan bernilai ekonomi tinggi Desa Tanjung Gunung telah selesai dilaksanakan, kegiatan ini telah mencapai target capaian yang telah direncanakan. Selain itu, kegiatan ini mendapat sambutan yang besar dari para peserta. Hal ini dibuktikan dengan antusiasme peserta yang mengikuti dari awal hingga akhir acara. Masyarakat sangat aktif bertanya baik saat maupun setelah kegiatan berlangsung. Harapan dengan adanya kegiatan ini, produk abon dan keripik jamur tiram akan banyak permintaan dan mendapat respon positif dipasaran. Serta membuka lahan usaha baru bagi masyarakat yang berada pada usia produktif dan non produktif.

\section{DAFTAR PUSTAKA}

Cahyana dan Mucrodji, Budidaya dan Analisis Usaha Jamur Tiram. Jakarta: Penebar Swadaya, 1999.

Djarijah dan Abbas, Budidaya Jamur Tiram. Yogyakarta: Kanisius, 2001.

Erie Maulana, Panen Jamur Tiap Musim, Yogyakarta: Andi Offset, 2012, hal 1-2

Hasyim, Fidha, Budidaya Jamur Tiram. Yogyakarta, 2015.

Indra Haryono, dkk. Wirausaha Produk Olahan Jamur Tiram Putih. PKM
Palangka Raya: Universitas Palangka Raya, 2012. 